\author{
Jurnal Homepage: https://jurnal.uns.ac.id/jptk
}

\title{
PENGEMBANGAN MULTIMEDIA PEMBELAJARAN FWA DAN BALANS RODA BERBASIS FLASH PADA KOMPETENSI PEMELIHARAAN RODA \& BAN SMK HARAPAN MULYA KENDAL
}

\author{
Ahmad Sulaiman ${ }^{1}$ dan Masugino ${ }^{1}$ \\ ${ }^{1}$ Prodi Pendidikan Teknik Otomotif, Fakultas Teknik, Universitas Negeri Semarang \\ Email : sulaiman07@students.unnes.ac.id
}

\begin{abstract}
Abstrak
Penelitian bertujuan untuk mengetahui kelayakan dan efektifitas penggunaan multimedia pembelajaran FWA dan balans roda. Penelitian merupakan jenis penelitian 4D. Subjek penelitian adalah siswa kelas XI Teknik Kendaraan Ringan SMK Harapan Mulya. Hasil penelitian menunjukkan multimedia pembelajaran FWA dan balans roda layak digunakan sebagai media pembelajaran berdasarkan hasil penilaian ahli materi sebesar $83,01 \%$ atau termasuk kategori layak dan ahli media sebesar 94,70\% atau termasuk kategori sangat layak. Terdapat perbedaan signifikan peningkatan hasil belajar siswa pada kelas eksperimen dibandingkan kelas kontrol, dimana $t_{\text {hitung }}$ sebesar 3,66 $>t_{\text {tabel }} 2,05$. Peningkatan hasil belajar kelas eksperimen menggunakan uji gain mendapat skor 0,445 menunjukkan peningkatan kategori sedang, dibandingkan kelas kontrol yang mendapat skor uji gain sebesar 0,236 menunjukkan peningkatan kategori rendah.
\end{abstract}

Kata kunci : Multimedia pembelajaran, FWA, Balans roda.

\begin{abstract}
This study was aimed at finding out the feasibility and the effectiveness of the use of learning multimedia FWA \& wheel balancing. This research used 4D model. The subject of this study were the students of grade XI Automotive Departement of Vocational High School Harapan Mulya. This study revealed that learning multimedia of FWA and wheel balancing proper to use as a learning multimedia based on the assessment of material experts was 83,01 $\%$ or proper to use and the assessment of media experts was $94,70 \%$ or very proper to use. There was significant improvement of the result of the study using learning multimedia compared without using learning multimedia, as result of $t_{\text {count }}=3,66>t_{\text {table }}=2,05$. The improvement calculated using gain analysis showed medium category improvement on experimental class with 0,445 gain score, whereas in control class showed low category improvement with 0,236 gain score.
\end{abstract}

Keywords $\quad$ : Learning multimedia, FWA, Wheel balancing 


\section{PENDAHULUAN}

Pendidikan merupakan sarana untuk mencetak sumber daya manusia yang unggul dan kompetitif agar dapat bersaing di kancah global. Keberhasilan pendidikan tentu tak terlepas dari proses belajar mengajar yang dilakukan. Keberhasilan pembelajaran ditentukan oleh beberapa faktor salah satunya yaitu media pembelajaran yang digunakan oleh pendidik dalam menyampaikan materi pembelajaran.

Hasil belajar siswa pada pembelajaran teori siswa pada kompetensi pemeliharaan roda dan ban pada SMK Harapan Mulya Kendal cenderung rendah bila dibandingkan dengan hasil belajar praktek. Hal ini dapat dibuktikan dengan masih banyaknya nilai teori siswa yang masih berada dibawah KKM yang ditentukan.

Media pembelajaran flash dipilih penulis karena lebih mudah dipergunakan tanpa perlu menggunakan aplikasi tambahan tertentu untuk dapat mengaksesnya. Selain itu, dari sisi konten media berbasis flash juga lebih variatif karena dapat memuat banyak jenis konten mulai dari penggunaan media berupa animasi, video, gambar, audio, dan kustomisasi desain media yang lebih fleksibel.

Media atau multimedia yang dipergunakan dalam pendidikan memberi gambaran dimana semua media, teks, grafik, audio/ suara, animasi dan video berada dalam satu model perangkat lunak yang dapat menjelaskan atau menggambarkan suatu program pendidikan(Munir, 2013:21).

Dengan mengkombinasikan berbagai model pembelajaran untuk mencakup seluruh karakteristik siswa, pendekatan kognitif, problem solving, dan cara berpikir siswa menjadi metode yang dominan untuk menerima informasi (Ocepek et, al., 2013:353).

Tujuan dari penelitian ini antara lain untuk mengetahui kelayakan multimedia pembelajaran FWA dan Balans roda berbasis Adobe flash CS6 dan untuk mengetahui peningkatan hasil belajar siswa kelas XI SMK Harapan Mulya Kendal tanpa menggunakan multimedia dan dengan menggunakan multimedia pembelajaran FWA dan Balans roda berbasis Adobe flash CS6.

\section{METODE PENELITIAN}

Model penelitian yang digunakan yaitu model 4D yang dikemukakan oleh Thiagarajan yang merupakan perpanjangan dari Define (pendefinisian masalah), Design (perancangan), Development (pengembangan), dan Dissemination (penyebarluasan produk) (Sugiyono,2016:39). Produk akan dievaluasi tingkat kelayakan nya dari sisi konten yaitu oleh ahli materi dan dari sisi desain multimedia yaitu oleh ahli media serta untuk menguji keefektifan produk maka akan dilakukan uji cba lapangan.

Untuk menguji kelayakan media sebelum digunakan secara masal maka perlu dievaluasi kelayakan multimedia baik dari segi materi maupun desain multimedia. Validitas materi akan diuji oleh dua orang ahli materi dan validitas desain media akan diuji oleh dua orang ahli media.

Desain uji coba lapangan menggunakan penelitian eksperimen dengan model penelitian True Experimental Design jenis pretest-postest control group design dimana terdapat dua kelompok yang dipilih secara random kemudian diberi pretest untuk mengetahui keadaan awal kelompok eksperimen dan kelompok kontrol. 


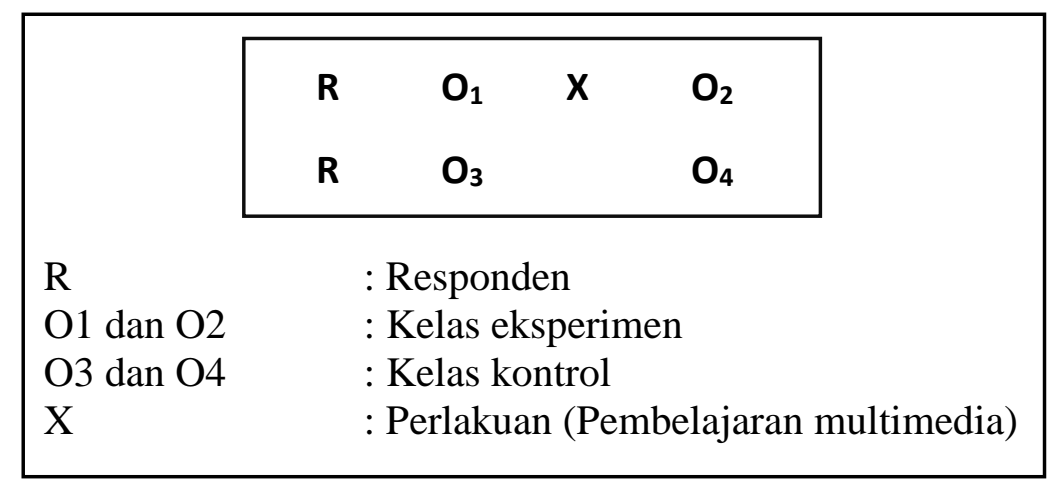

Gambar 1. Desain Penelitian

$\mathrm{O}_{1}$ merupakan pretest/ kondisi awal kelompok eksperimen sebelum diberi treatment dan $\mathrm{O}_{2}$ merupakan posttest atau keadaan akhir peserta didik setelah diberi treatment $(\mathrm{X})$ berupa proses belajar mengajar menggunakan multimedia. Sedangakan $\mathrm{O}_{3}$ merupakan kondisi awal / pretest pada kelompok kontrol dan $\mathrm{O}_{4}$ merupakan kondisi akhir/ posttest kelompok kontrol tanpa adanya perlakuan. Hasil pretest baik apabila kelompok eksperimen tidak berbeda secara signifikan. Pengaruh perlakuan adalah $\left(\mathrm{O}_{2}-\mathrm{O}_{1}\right)-\left(\mathrm{O}_{4}\right.$ $\mathrm{O}_{3}$ ) (Sugiyono, 2016:506).

\section{HASIL DAN PEMBAHASAN}

Hasil penilaian ahli materi berdasarkan aspek kesesuaian materi, kualitas materi dan kualitas soal yang telah dikonversi kedalam skala klasifikasi kelayakan media dapat dilihat pada tabel 1 .

Tabel 1. Analisis penilaian ahli materi

\begin{tabular}{|c|c|c|c|c|c|}
\hline \multirow[b]{2}{*}{ No. } & \multirow[b]{2}{*}{ Penilai } & \multicolumn{3}{|c|}{ Aspek } & \multirow[b]{2}{*}{$\begin{array}{c}\text { Skor rata-rata } \\
(\%)\end{array}$} \\
\hline & & $\begin{array}{c}\text { Keseuaian } \\
\text { materi }\end{array}$ & $\begin{array}{c}\text { Kualitas } \\
\text { materi }\end{array}$ & Kualitas soal & \\
\hline 1. & Ahli materi 1 & $74,3 \%$ & $67,3 \%$ & $70 \%$ & $70,53 \%$ \\
\hline 2. & Ahli materi 2 & $82,9 \%$ & $83,6 \%$ & $100 \%$ & $88,83 \%$ \\
\hline 3. & Ahli materi 3 & $90 \%$ & $89,1 \%$ & $90 \%$ & $89,7 \%$ \\
\hline \multicolumn{2}{|c|}{ Total skor rata-rata } & $82,38 \%$ & $80 \%$ & $86,67 \%$ & $83,01 \%$ \\
\hline \multicolumn{2}{|c|}{ Klasifikasi } & Layak & Layak & Sangat Layak & Layak \\
\hline
\end{tabular}

Berdasarkan hasil uji tanggapan ahli materi melalui instrumen angket didapatkan hasil pada aspek kesesuaian materi mendapat persentase kelayakan ratarata sebesar $82,38 \%$ atau masuk dalam kriteria layak. Pada aspek kualitas materi mendapatkan persentase kelayakan ratarata sebesar $80 \%$ atau termasuk dalam kriteria layak. Sedangkan pada aspek kualitas soal mendapatkan persentase kelayakan rata-rata sebesar $86,67 \%$ atau termasuk dalam kriteria sangat layak, sehingga secara keseluruhan persentase kelayakan rata-rata oleh ahli materi sebesar $83,01 \%$ atau termasuk dalam kriteria layak. Hasil penilaian kelayakan media oleh ahli materi dapat dilihat pada gambar 2 . 


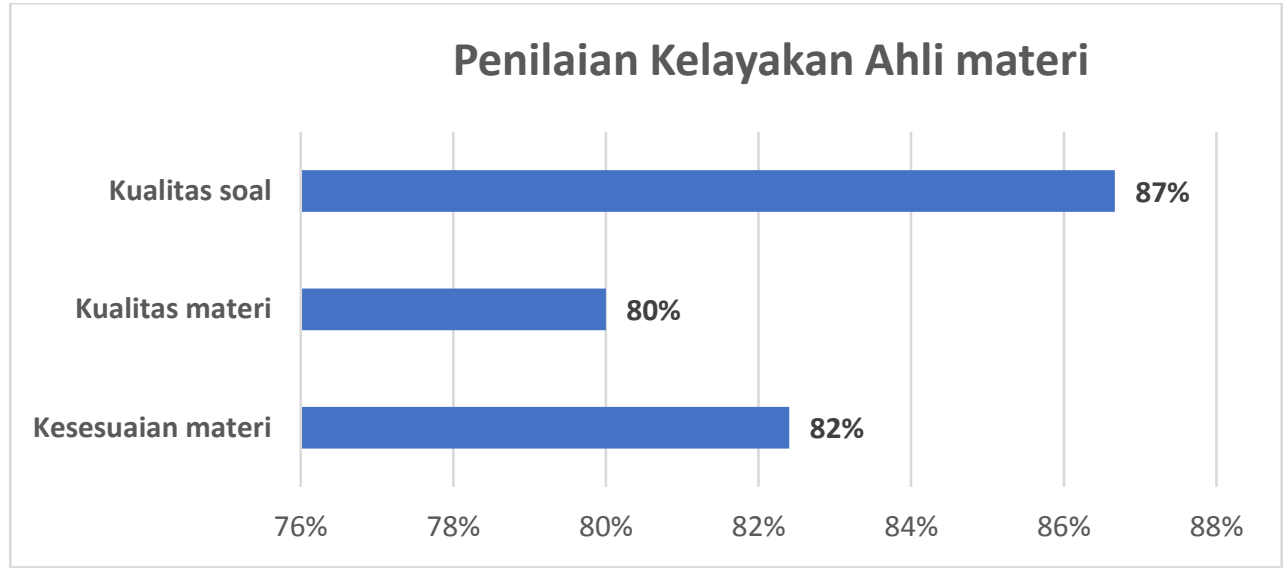

Gambar 2. Diagram penilaian kelayakan ahli materi

Tabel 2. Analisis penilaian ahli media

\begin{tabular}{lcccc}
\hline \multirow{2}{*}{ No. } & Penilai & \multicolumn{2}{c}{ Aspek } & Skor rata-rata \\
\cline { 2 - 4 } & & $\begin{array}{c}\text { Komunikasi } \\
\text { visual }\end{array}$ & Pemrograman & \\
\hline 1. & Ahli media 1 & $95,79 \%$ & $100 \%$ & $97,89 \%$ \\
\hline 2. & Ahli media 2 & $90,53 \%$ & $92,50 \%$ & $91,51 \%$ \\
\hline Total skor rata-rata & $93,16 \%$ & $96,25 \%$ & $94,70 \%$ \\
\hline Klasifikasi & Sangat layak & Sangat layak & Sangat layak \\
\hline
\end{tabular}

Berdasarkan hasil uji tanggapan ahli media melalui instrumen angket didapatkan hasil pada aspek komunikasi visual mendapat persentase kelayakan rata-rata sebesar 93,10\% atau masuk dalam kriteria sangat layak. Pada aspek pemrograman mendapatkan persentase kelayakan rata- rata sebesar $96,25 \%$ atau termasuk dalam kriteria sangat layak, sehingga secara keseluruhan persentase kelayakan rata-rata oleh ahli media sebesar $94,70 \%$ atau termasuk dalam kriteria sangat layak. Hasil penilaian kelayakan media oleh ahli media dapat dilihat pada gambar 3 .

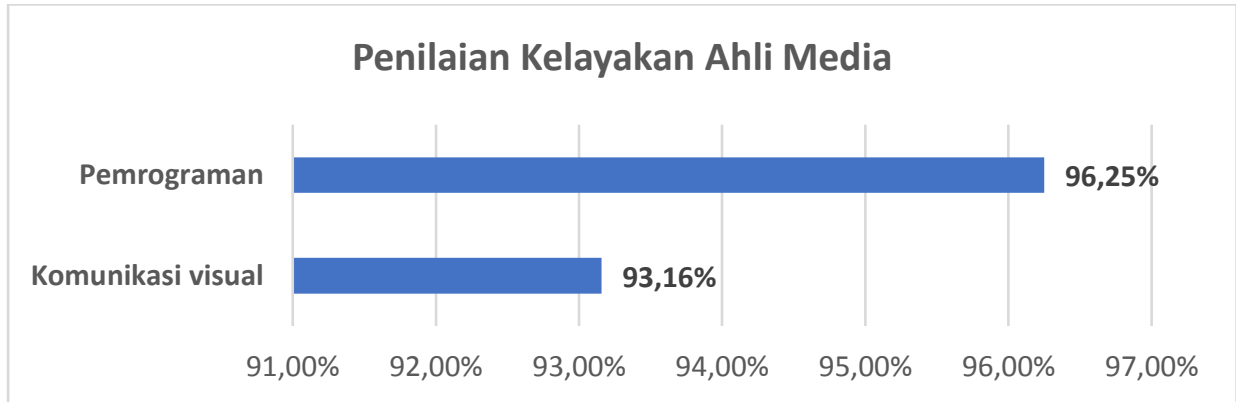

Gambar 3. Diagram penilaian kelayakan ahli media

Berdasarkan analisis instrumen soal didapatkan 30 dari 40 item soal yang layak digunakan sebagai instrumen tes pretestpostest. Item soal nomor 2,5,12,30,34,36,38,39 dan 40 tidak dapat digunakan sebagai instrumen uji karena tidak memenuhi indeks daya beda, sedangkan item soal nomor 13 tidak memenuhi syarat uji validitas instrumen, sehingga item soal dengan nomor-nomor tersebut tidak digunakan peneliti. 
1. Uji Normalitas

Uji normalitas dianalisis menggunakan rumus chi kuadrat. Hasil uji normalitas pretest kelas kontrol dan kelas eksperimen dapat dilihat pada tabel 4.17 (tabel perhitungan uji normalitas terlampir).

Tabel 3. Hasil uji normalitas pretest kelas kontrol dan eksperimen

\begin{tabular}{cccl}
\hline Kelas & $\begin{array}{c}\mathbf{X}^{\mathbf{2}} \\
\text { hitung }\end{array}$ & $\begin{array}{c}\mathbf{X}^{\mathbf{2}} \\
\text { tabel }\end{array}$ & Hasil uji \\
\hline Kontrol & 4,984 & 7,815 & Normal \\
\hline Eksperimen & 5,194 & 7,815 & Normal \\
\hline
\end{tabular}

Berdasarkan tabel uji normalitas pretest diatas dapat diketahui bahwa hasil uji normalitas diperoleh nilai $\mathrm{X}^{2}$ hitung 4,984 untuk kelas kontrol dan nilai $X^{2}$ hitung 4,194 untuk kelas eksperimen $\mathrm{X}^{2}$ tabel pada taraf signifikansi 5\% adalah sebesar 7,81. Data dapat dikatakan berdistribusi normal apabila $X^{2}$ hitung $<X^{2}$ tabel, karena $X^{2}{ }_{\text {hitung data }}$ uji normalitas pada kelompok kontrol 4,984 $<\mathrm{X}^{2}$ tabel maka data berdistribusi normal dan $\mathrm{X}^{2}$ hitung data uji normalitas pada kelompok eksperimen 4,194 maka data berdistribusi normal.

Tabel 4. Hasil uji normalitas postest kelas kontrol dan eksperimen

\begin{tabular}{cccl}
\hline Kelas & $\begin{array}{c}\mathbf{X}^{\mathbf{2}} \\
\text { hitung }\end{array}$ & $\begin{array}{c}\mathbf{X}^{\mathbf{2}} \\
\text { tabel }\end{array}$ & Hasil uji \\
\hline Kontrol & 3,700 & 7,815 & Normal \\
\hline Eksperimen & 5,682 & 7,815 & Normal \\
\hline
\end{tabular}

Berdasarkan tabel uji normalitas postest diatas dapat diketahui bahwa hasil uji normalitas diperoleh nilai $\mathrm{X}^{2}$ hitung 3,700 untuk kelas kontrol dan nilai $X^{2}$ hitung 5,682 untuk kelas eksperimen $\mathrm{X}^{2}$ tabel pada taraf signifikansi 5\% adalah sebesar 7,81. Data dapat dikatakan berdistribusi normal apabila $X^{2}{ }_{\text {hitung }}<X^{2}$ tabel, karena $X^{2}{ }_{\text {hitung }}$ data 4. Uji gain

Berdasarkan hasil uji gain dapat diketahui bahwa pada kelas kontrol hasil skor uji gain sebesar 0,236 atau termasuk peningkatan uji normalitas pada kelompok kontrol 3,700 $<\mathrm{X}^{2}$ tabel maka data berdistribusi normal dan $\mathrm{X}^{2}$ hitung data uji normalitas pada kelompok eksperimen 5,682 maka data berdistribusi normal.

2. Uji homogenitas

Tabel 5. Hasil uji homogenitas

\begin{tabular}{cccc}
\hline Kelas & $\mathbf{F}_{\text {hitung }}$ & $\mathbf{F}_{\text {tabel }}$ & Hasil uji \\
\hline Pretest & 0,415 & 0,54 & Homogen \\
\hline Postest & 0,439 & 0,54 & Homogen \\
\hline
\end{tabular}

Berdasarkan tabel uji homogenitas diperoleh $F_{\text {hitung }}$ pretest sebesar 0,415 dan diperoleh $F_{\text {hitung }}$ postest sebesar 0,439. F tabel $_{\text {t }}$ untuk dk1 30 dan dk2 30-1 = 0,54 pada taraf signifikansi 5\%. Fhitung pretest sebesar $0,415<F_{\text {tabel }}$ sehingga data pretest homogen, sedangkan $\mathrm{F}_{\text {hitung }}$ postest sebesar $0,439<F_{\text {tabel }}$ sehingga data postest homogen.

\section{Uji t}

Tabel 6. Hasil uji t kelompok kontrol dan kelompok eksperimen

\begin{tabular}{cccc} 
Kelas & $\mathbf{t}_{\text {hitung }}$ & $\mathbf{t}_{\text {tabel }}$ & Hasil uji \\
\hline Pretest & 0,62 & 2,05 & Tidak ada perbedaan \\
\hline Postest & 3,66 & 2,05 & Ada perbedaan \\
\hline
\end{tabular}

Berdasarkan tabel uji $\mathrm{t}$ dapat diketahui bahwa pada pretest diperoleh

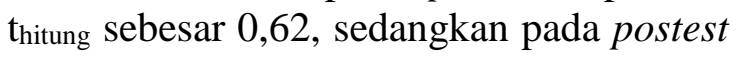
$t_{\text {hitung sebesar 3,66. Pada koefisien alpha }=}$ $5 \%$ dengan $\mathrm{db}=30-1=29$ diperoleh $\mathrm{t}_{\text {tabel}(0.95)(29)}$ adalah 2,05, karena pada pretest $t_{\text {hitung }}$ sebesar $0,62<t_{\text {tabel }}$ maka dapat disimpulkan tidak ada perbedaan pada hasil pretest antara kelas eksperimen dengan kelas kontrol. Hasil postest $t_{\text {hitung }}$ sebesar 3,66 > $t_{\text {tabel }}$ sehingga dapat disimpulkan terdapat perbedaan hasil postest pada kelas eksperimen dibandingkan kelas kontrol.

hasil belajar kriteria rendah sedangkan pada kelas eksperimen diperoleh hasil skor uji gain sebesar 0,445 atau termasuk peningkatan hasil belajar kriteria sedang. 
Tabel 7. Hasil uji gain kelas kontrol dan kelas eksperimen

\begin{tabular}{cccccc}
\hline Kelas & $\begin{array}{c}\text { Nilai rerata } \\
\text { pretest }(\mathbf{\%})\end{array}$ & $\begin{array}{c}\text { Nilai rerata } \\
\text { postest (\%) }\end{array}$ & $\begin{array}{c}\text { Skor uji } \\
\text { Gain }\end{array}$ & Peningkatan & Simpulan \\
\hline Kontrol & 62,33 & 71,22 & 0,236 & 8,89 & Rendah \\
\hline Eksperimen & 61,33 & 78,56 & 0,445 & 17,23 & Sedang \\
\hline
\end{tabular}

Berdasarkan hasil analisis data diatas dapat disimpilkan terdapat peningkatan hasil belajar yang signifikan dengan menggunakan multimedia interaktif
FWA dan balans roda dibandingkan tanpa menggunakan media pembelajaran FWA dan balans roda. Perbedaan peningkatan hasil belajar dapat dilihat pada gambar 4 .

\section{PERBEDAAN PENINGKATAN RERATA HASIL BELAJAR ANTARA KELAS KONTROL DAN KELAS EKSPERIMEN}

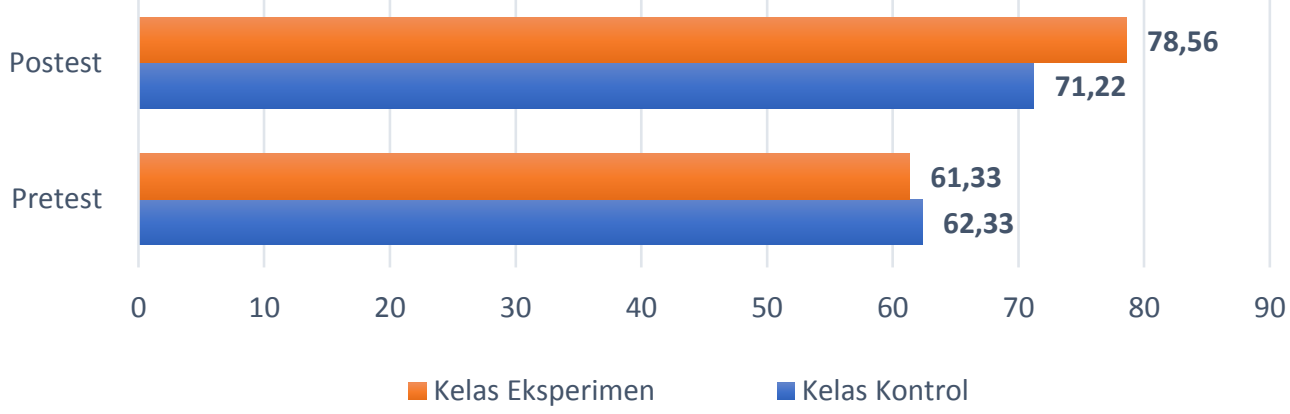

Gambar 4. Diagram perbedaan peningkatan hasil belajar kelas eksperimen dengan kelas kontrol

\section{SIMPULAN}

Multimedia pembelajaran interaktif FWA dan balans roda berbasis flash layak digunakan sebagai media pembelajaran, dengan rata-rata hasil penilaian ahli materi sebesar $83,01 \%$ atau termasuk kategori layak dan ahli media sebesar $94,70 \%$ atau termasuk kategori sangat layak.

Terdapat perbedaan signifikan peningkatan hasil belajar siswa dengan menggunakan multimedia interaktif FWA dan balans roda dibandingkan tanpa menggunakan multimedia, dimana thitung sebesar 3,66 $>t_{\text {tabel }} 2,05$. Hasil evaluasi ratarata kelas eksperimen (pembelajaran dengan multimedia) sebelum menggunakan multimedia sebesar $61,33 \%$ meningkat menjadi $78,56 \%$ setelah menggunakan multimedia. Hasil evaluasi rata-rata kelas kontrol (tanpa menggunakan multimedia) sebelum pembelajaran sebesar 62,33\% meningkat menjadi $71,22 \%$. Peningkatan hasil belajar dengan multimedia FWA dan balans roda pada kelas eksperimen menggunakan analisis uji gain mendapat skor 0,445 menunjukkan peningkatan kategori sedang.

\section{DAFTAR PUSTAKA}

Munir. 2013. Multimedia Konsep dan Aplikasi dalam Pendidikan. Bandung: Alfabeta

Ocepek, U., Bosnić, Z., Šerbec, I. N., \& Rugelj, J. (2013). Exploring the relation between learning style models and preferred multimedia types. Computers \& Education, 69, 343-355.

Sugiyono. 2016. Metode Penelitian \& Pengembangan (Research and Development/ $R \& D)$. Bandung: Afabeta. 